\title{
Salvage concurrent radio-chemotherapy for post-operative local recurrence of squamous-cell esophageal cancer
}

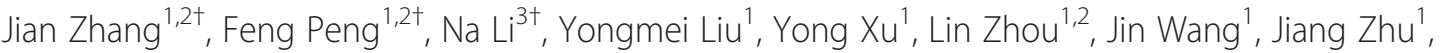 \\ Meijuan Huang ${ }^{1,2}$ and Youling Gong ${ }^{1,2^{*}}$
}

\begin{abstract}
Purpose: To evaluate the treatment outcome of salvage concurrent radio-chemotherapy for patients with locorecurrent esophageal cancer after surgery.

Methods: 50 patients with loco-recurrent squamous-cell cancer after curative esophagectomy were retrospectively analyzed. Patients were treated with radiotherapy (median $60 \mathrm{~Gy}$ ) combined with chemotherapy consisting of either 5-fluorouracil (5-FU) plus cisplatin (DDP) (R-FP group) or paclitaxel plus DDP (R-TP group).

Results: The median follow-up period was 16.0 months. The 1-year and 3-year survival rates were 56\% and 14\%, respectively. The median progression-free survival (PFS) and overall survival (OS) time was 9.8 and 13.3 months respectively. There was no statistical significance of the PFS of the two groups. The OS (median 16.3 months) in the R-TP group was superior to that in the R-FP group (median: 9.8 months) $(p=0.012)$. Among the patients who had received $\geq 60$ Gy irradiation dose, the median PFS (10.6 months) and OS (16.3 months) were significantly superior to the PFS (8.7 months) and OS (11.3 months) among those patients did not (all $p<0.05)$. Grade 3 treatment-related gastritis were observed in 6 (27.3\%) and 7 (25\%) patients in the R-FP and R-TP group respectively. By univariate survival analysis, the age ( $<60$ years), TP regimen and higher irradiation dose might improve the OS of such patients in present study.
\end{abstract}

Conclusions: For those patients with post-operative loco-recurrent squamous-cell esophageal carcinoma, radiotherapy combined with either FP or TP regimen chemotherapy was an effective salvage treatment. Younger age, treatment with the TP regimen and an irradiation dose $\geq 60$ Gy might improve the patients' treatment outcome.

Keywords: Squamous-cell esophageal cancer, Post-operative local recurrence, Salvage radio-chemotherapy, Treatment outcomes, Toxicity

\section{Introduction}

Curative esophagectomy with radical lymph node dissection is the primary treatment for early stage esophageal carcinoma [1,2]. However, the 5-year survival rate remains only around $40 \%$ [3]. Loco-regional recurrence still is the major type of failure in those patients following surgery

\footnotetext{
* Correspondence: gongyouling@gmail.com

${ }^{\dagger}$ Equal contributors

'Department of Thoracic Oncology and Radiation Oncology, Cancer Center, West China Hospital, Sichuan University, Chengdu 610041, PR China

${ }^{2}$ State Key Laboratory of Biotherapy, West China Hospital, Sichuan University, Chengdu 610041, PR China

Full list of author information is available at the end of the article
}

[4,5]. Depending on performance status, there are a number of patients which might tolerate the salvage treatment. In these patients, a potential for cure still exists.

Since 2000, radiotherapy, chemotherapy or chemoradiotherapy have been demonstrated as the possible salvage treatment for post-operative local recurrent esophageal carcinoma, with reported the median OS of 7.0-16.0 months [6-16]. In a phase II trial, Jingu et al. from Japan reported that radiotherapy (60 Gy/30 fractions) combined with nedaplatin and 5-FU is a safe and effective salvage option for loco-recurrent esophageal carcinoma, achieving an impressive median OS of 39 months [17].

\section{Ciomed Central}


In our experiences, the patients with loco-recurrent esophageal carcinoma and good performance status could be considered as the potentially curative ones. Radio-chemotherapy consisting of fluorouracil (5-FU)/ DDP (FP) or paclitaxel/DDP (TP) regimen has been used as the salvage and definitive treatment in our practice, according to the National Comprehensive Cancer Network (NCCN) Guidelines [18].

In this study, we retrospectively evaluated the survival of the identical patients treated with salvage concurrent radio-chemotherapy, in order to analyze the impacts of the chemotherapy regimen (FP or TP) and the irradiation dose on the treatment outcome of post-operative local recurrences of squamous-cell esophageal carcinoma.

\section{Patients and methods Patients' data}

A loco-regional recurrence was defined as anastomotic recurrence or lymph node metastasis in supraclavicular and mediastinum regions; only in patients with an initial diagnosis of lower thoracic carcinoma, the abdominal lymph node metastasis was considered as local recurrences. Between March 2005 and December 2009, a total of 50 esophageal carcinoma patients received chemoradiotherapy for loco-regional recurrence at West China hospital and Second Affiliated Hospital of Anhui Medical University. Each patient had undergone an R0 resection including extended lymph node dissection and had histologically proven squamous-cell eaophageal carcinoma. All of the patients gave their informed consent before treatment, which was in accordance with the Declaration of Helsinki [19] and also approved by the Ethics Committee of our hospitals.

The basic and clinical characteristics of the studied patients are summarized in Table 1. The median age of the patients was 54.2 years (range: $39-64$ years); most of them were male and with the Eastern Cooperative Oncology Group (ECOG) performance status score 0-1 (47/50, 94.0\%). The initial tumor stage (Staging system, American Joint Committee on Cancer) [20] after surgery in the present study were 17 stage I-II and 33 stage III-IV respectively. The median time between surgery and recurrence was 13.0 months (range: 5.0-32.0 months). Local recurrence was diagnosed by computed tomography (CT), upper gastrointestinal endoscopy and ultrasonography. There were 7 (12.7\%), 23 (41.8\%), 19 (34.5\%) and $6(10.9 \%)$ recurrences in anastomotic, supraclavicular, mediastinal and abdominal regions respectively, and 5 patients were confirmed having 2 recurrent sites respectively.

\section{Salvage radio-chemotherapy Radiotherapy}

All patients underwent initial CT simulation, then the three-dimentional conformal radiotherapy (3D-CRT) and
Table 1 Basic and clinical characteristics of the patients in present study $(n=50)$

\begin{tabular}{|c|c|}
\hline Characteristics & Number of patients (\%) \\
\hline \multicolumn{2}{|l|}{ Age (years) } \\
\hline Median (range) & $54(39-64)$ \\
\hline \multicolumn{2}{|l|}{ Gender } \\
\hline Male/Female & $42(84.0) / 8(16.0)$ \\
\hline \multicolumn{2}{|l|}{ ECOG $^{a}$ performance status } \\
\hline $0-1$ & $47(94.0)$ \\
\hline 2 & $3(6.0)$ \\
\hline \multicolumn{2}{|l|}{ Pathology } \\
\hline Squamous-cell carcinoma (SCC) & $50(100.0)$ \\
\hline \multicolumn{2}{|l|}{ Tumorstage $^{b}$ after surgery } \\
\hline$|-| \mid$ & $17(34.0)$ \\
\hline $\mathrm{III-IV}$ & $33(66.0)$ \\
\hline \multicolumn{2}{|l|}{ Time form surgery to recurrences (months) } \\
\hline Median (range) & $13.0(5.0-32.0)$ \\
\hline \multicolumn{2}{|l|}{ Sites of recurrence ${ }^{c}$} \\
\hline Anastomotic & $7(14.0)$ \\
\hline Supraclavicular lymph nodes & $18(36.0)$ \\
\hline Mediastinal lymph nodes & $15(30.0)$ \\
\hline Abdominal lymph nodes & $5(10.0)$ \\
\hline Supraclavicular/mediastinal lymph nodes & $4(8.0)$ \\
\hline Supraclavicular/abdominal lymph nodes & $1(2.0)$ \\
\hline
\end{tabular}

were usually applied for treament. Intensity-modulated radiotherapy (IMRT) was used if any supraclavicular lymph node was included as a target. The gross tumor volume (GTV) included all known gross disease as determined by the imaging and endoscopic findings. The clinical target volume (CTV) was defined as the GTV plus a 2-3 $\mathrm{cm}$ radial margin. If the target was coutoured in the supraclavicular region, the correlated lymphatic drainage regions was coutoured as the CTV, extending to the cricothyroid membrane. The planning target volume (PTV) was defined as the CTV plus a $0.5 \mathrm{~cm}$ margin in all direction, respectively. The patients received a conventional-fraction schedule: 1.8-2.0 Gy per fraction and 5 fractions per week with a 6-MV linear accelerator. As shown in Table 2, the median irradiation dose for the PTV was $60 \mathrm{~Gy}$, with a range of 50.4-64 Gy. The dose constraint for the spinal cord was a maximum dose

Table 2 Response to treatment

\begin{tabular}{llll}
\hline & $\begin{array}{l}\text { Complete } \\
\text { response (CR) }\end{array}$ & $\begin{array}{l}\text { Partial } \\
\text { response (PR) }\end{array}$ & $\begin{array}{l}\text { Stable } \\
\text { disease (SD) }\end{array}$ \\
\hline R-TP group & $5(17.9 \%)$ & $15(53.6 \%)$ & $8(28.3 \%)$ \\
\hline R-FP group & $5(22.7 \%)$ & $11(50.0 \%)$ & $6(27.3 \%)$ \\
\hline
\end{tabular}


$<45$ Gy. For lungs, the mean dose and $V_{20}$ were limited within 15 Gy and 30\% respectively.

\section{Chemotherapy}

The chemotherapy and radiotherapy started at the same day. The regimens consisting of either 5 -FU $500 \mathrm{mg} / \mathrm{m}^{2} /$ day for five days plus DDP $75 \mathrm{mg} / \mathrm{m}^{2}$ on day one per 4 weeks or paclitaxel $135 \mathrm{mg} / \mathrm{m}^{2}$ and DDP $75 \mathrm{mg} / \mathrm{m}^{2}$ on day one per 3 weeks. Only the grade 3 or higher treatmentrelated esophagitis were observed and if prolonged, the chemotherapy was discontinued; otherwise the chemotherapy was suspended until recovery and reduced the regimen dose by $25 \%$ in the subsequent cycle.

\section{Treatment assessment}

Evaluation of treatment response was carried out according to Response Evaluation Criteria in Solid Tumors (RECIST criteria) [21]. Disappearance of the all GTVs was designated to indicate complete response (CR) on CT persisting for more than 4 weeks. A partial response (PR) was defined as a minimum of a $30 \%$ decrease in the sum of the longest diameter of target lesions. A disease was defined stable (SD) where there was neither a sufficient shrinkage to qualify for a PR nor a sufficient increase in the target lesions, and progressive (PD), when there was at least a $20 \%$ increase in the sum of the longest diameter of the target lesions or appearance of new lesions. Follow-up evaluations were performed every 2 to 3 months for the first year and every 6 months thereafter by CT.

Toxicities were evaluated according to the National Cancer Institute Common Toxicity Criteria version 3.0.

\section{Statistical methods}

Statistical analyses were performed using the SPSS software (version 13.0). The progression-free survival (PFS) time was measured from the date the treatment began to the date of the disease progression and the overall survival (OS) time was considered from the start of treatment to date of data analysis or date of loss from follow-up for patients alive. Patients without disease relapse or progression who discontinued the study for any reason were censored at the last on study tumor assessment date. The rates of PFS and OS curves depending on the different factors were calculated using the method of Kaplan-Meier analysis and were compared using a log-rank test. A $p$ value $<0.05$ was considered with statistical significance. Also, Cox's proportional hazards regression model was used for univariate survival analysis. Patient age, gender, staging after surgery, time interval between surgery and recurrence, irradiation dose, chemothrapy regimen, tumor response to treatment were put into univariate analysis. Due to the small patient numbers, multivariate analysis was not performed.

\section{Results}

The median follow-up time for the studied patients was 16.0 months (range: 10.0-44.0 months) and the median time interval between surgery and recurrence was 13.0 months (range: 5.0-32.0 months). All patients completed the radiotherapy treatment. In present study, $72.7 \%(16 / 22)$ and $75 \%(21 / 28)$ patients had received 2 cycles of chemotherapy in the FP and TP group respectively. And the remaining patients had received at least 1 cycle of chemotherapy.

\section{Responses to treatment}

All patients were assessed as having had a response (details shown in Table 2). In the R-FP group, 5 (22.7\%), $11(50 \%)$ and 6 (27.3\%) patients showed CR, PR and SD, respectively. And in the R-TP group, these numbers were $5(17.9 \%), 15(53.6 \%)$ and $8(28.3 \%)$ respectively. The overall responses were $72.7 \%(16 / 22)$ and $71.7 \%$ (20/28) in the R-FP and R-TP group respectively.

\section{Follow-up}

Patient follow-up studies continued until December 2011, with no one lost to follow-up. The 1-year and 3year survival rates were $56 \%$ and $14 \%$ respectively. The median PFS of the whole group was 9.8 months (range: 4.7-41.0 months) and the median OS of all patients was 13.3 months (range: 5.4-44.0 months).

In sub-group analysis, the median PFS and OS were 9.8 months [95\% confidential interval (CI) 9.410.1 months] and 9.8 months (95\% CI 9.4-10.2 months) in the R-FP group respectively (Figure 1). The patients receiving the TP regimen had the similar outcomes of the PFS (9.8 months, 95\% CI 7.5-12.0 months) but a significant improvement of the OS (16.3 months, 95\% CI 14.5-18.1 months) $(p=0.012)$, compared to those patients receiving the $\mathrm{FP}$ regimen.

In addition, the irradiation dose had a clear impact on the treatment outcomes in these evaluated patients (Figure 2). Patients receiving more than 60 Gy irradiation dose had significantly prolonged period in PFS (10.6 months, 95\% CI 7.8-13.3 months) and OS (16.3 months, 95\% CI 13.6-18.9 months) than those patients who received an irradiation dose less than 60 Gy (for PFS: 8.7 months, 95\% CI 6.5-10.8 months and for OS: 11.3 months, $95 \%$ CI 9.3-13.2 months) respectively ( $p=0.01$ and 0.04 , respectively).

\section{Treatment-related toxicities}

All the patients were evaluated for tretment-related toxicities (Table 3). The combination of radiotherapy and chemotherapy (either FP or TP regimens) were proved to be tolerable. The most common toxicities were the treatment-related gastritis and neutropenia. Grade 3 treatment-related gastritis were observed in 6 patients 

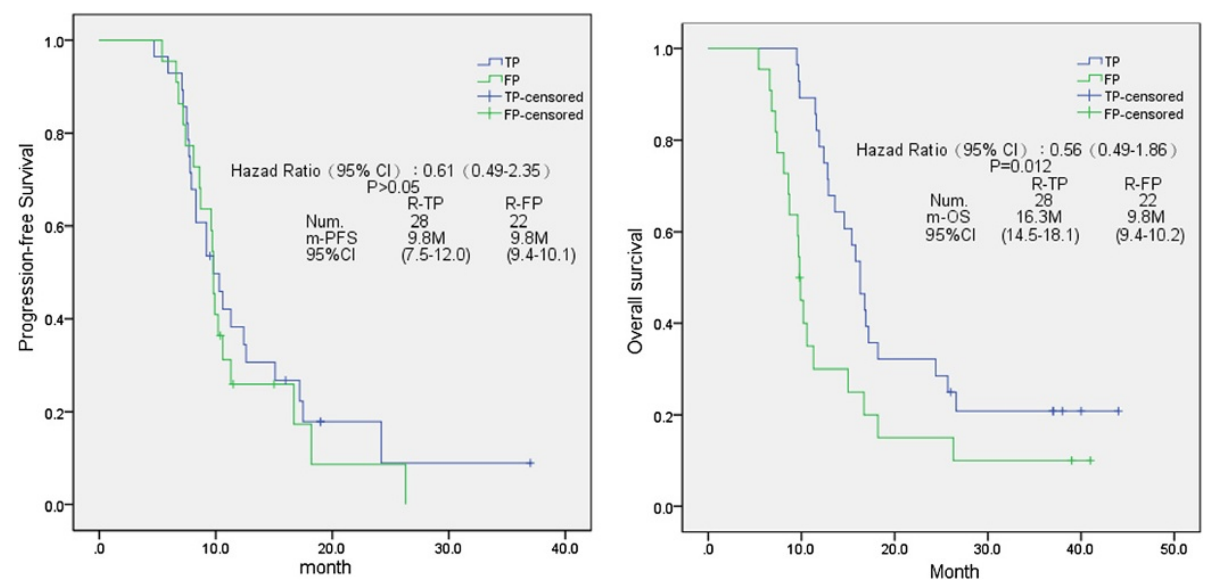

Figure 1 Kaplan-Meier analysis of progression-free survival (PFS) and overall survival (OS) in the present study, according to the chemotherapy regimen the patients received.

(27.3\%) and 7 patients (25.0\%) in the R-FP and R-TP group, respectively. Grade 3 neutropenia were observed in $7(31.8 \%)$ and $6(26.4 \%)$ patients in the R-FP and R-TP group, respectively. The other major grade 2 toxicities included the neutropenia, anemia and nausea/vomiting/ diarrhea. One patient receiving R-TP treatment had the grade 3 vomiting (3.6\%). No grade 4 or 5 toxicity was recorded among all the patients.

\section{Univariate survival analysis}

Due to the small number of the evaluated, only the univariate analysis was performed according to the basic and clinical characteristics of the patients. The details were shown in Table 4. The gender, disease stage after surgery, the responses to the treatment and irradiation dose did not significantly affected the survival time. While the patients' age ( $<60$ years), the chemotherapy regimen (TP) and irradiation dose more than 60 Gy showed the trends which could improve the overall survival of the patients in present study respectively $(p=0.048,0.025$ and 0.041 , respectively).

\section{Discussion}

Loco-regional recurrences after intial surgery in patients with esophageal cancer remain a serious challenge to clinical oncologists. The NCCN Guidelines pointed out that a highly selected group of patients with localregional tumor recurrence after initial surgery may be considered fit and able to tolerate concurrent radiochemotherapy with a potential for cure [18]. In a line with the previous studies, our data indicated that salvage concurrent radio-chemotherapy was an active and promising treatment strategy for such patients, reaching a median OS of 13.3 months with tolerable side-effects.

The present protocol of concurrent radio-chemotherapy was completed in $74 \%(37 / 50)$ of the patients, and no
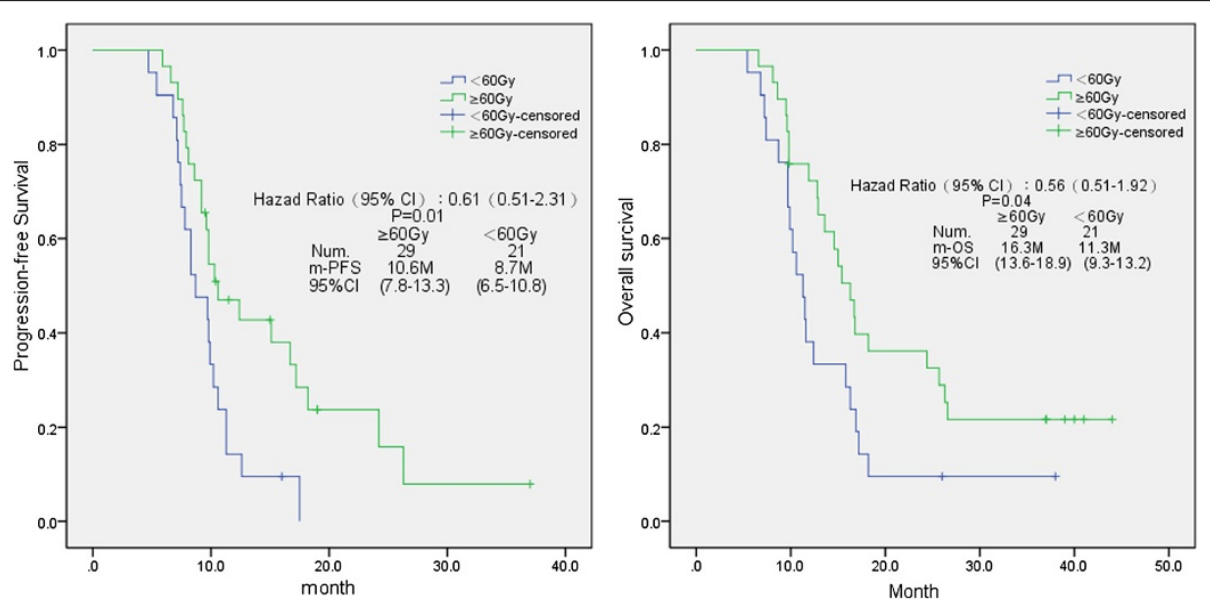

Figure 2 Kaplan-Meier analysis of progression-free survival (PFS) and overall survival (OS) in the present study, according to the irradiation dose the patients received. 
Table 3 Treatment-related toxicities (number $=22$ and 28 in R-FP and R-TP group respectively) ${ }^{a}$

\begin{tabular}{lccc}
\hline Toxicities & \multicolumn{1}{c}{ Toxicity grades, $\mathbf{n}$ (\%) } \\
\cline { 2 - 4 } & \multicolumn{1}{l}{ Grade $\mathbf{1}$} & Grade $\mathbf{2}$ & Grade $\mathbf{3}$ \\
\hline Hematological & $3(13.6) / 5(17.9)$ & $12(54.5) / 17(60.7)$ & $7(31.8) / 6(21.4)$ \\
\hline Neutropenia & $8(36.4) / 10(35.7)$ & $14(63.6) / 18(64.3)$ & $0 / 0$ \\
\hline Anemia & $17(77.3) / 18(64.3)$ & $5(22.7) / 10(35.7)$ & $0 / 0$ \\
\hline Thrombocytopenia & $3(13.6) / 7(25)$ & $19(86.4) / 20(71.4)$ & $0 / 1(3.6)$ \\
\hline Non-hematological & $2(9.1) / 3(10.7)$ & $14(63.6) / 18(64.3)$ & $6(27.3) / 7(25.0)$ \\
\hline Digestive tract side-effects ${ }^{b}$ &
\end{tabular}

serious treatment related toxicities were observed. The tumor response rate was nearly $72 \%$ in R-TP and R-FP group respectively, with a 3 -year survival rate of $14 \%$. These results are very similar to those reported in previous studies [13,15]. Yamashita et al. [13] reported the results of radiotherapy with or without chemotherapy at an average total dose of $56.6 \mathrm{~Gy}$. The median survival time was 13.8 months and 1-year survival rate was $56 \%$ in patients with patients with loco-regional recurrence of esophageal cancer after curative surgery. Recently, Baxi et al. from Princess Alexandra Hospital reported their treatment outcomes using DDP and 5-FU plus radiotherapy (range: 45-60 Gy) for recurrent esophageal cancer [15]. The 2-year survival rate of all patients was $21 \%$ and the median OS was 16 months. While the very impressive results of salvage radio-chemotherapy for such patients were reported by Jingu et al. [17] and the 3-year survival rate was $56.3 \%$ using radiotherapy combined with nedaplatin and 5-FU. But it was a small phase II study (patients' number $=30$ ), and these data had not been confirmed by further clinical investigations.
By sub-group analysis in the present study, the median OS of the 28 patients received R-TP regimen (16.3 months) was significantly superior than that of other patients who received R-FP regimen (9.8 months) $(p<0.05)$. According to our knowledge, there was no direct comparison between FP and TP regimen when combined with radiotehrapy in the definitive treatment for esophageal cancer. Recently, Ajani et al. reported that the regimen including 5-FU/DDP/paclitaxel with 50.4 Gy of radiation was associated with high morbidity, although it reached a 1 -year survival rate of $75.7 \%$ in RTOG 0113 trial [22]. So far, FP regimen still was the first choice in definitive radio-chemotherapy for esophageal cancer in the NCCN guidelines [18]. The possible reason that the poorer treatment outcomes using R-FP regimen in present study was the relative lower dosage of 5 -FU $\left(500 \mathrm{mg} / \mathrm{m}^{2} / \mathrm{D}, \mathrm{D} 1-5\right.$ per 4 weeks). In the trial INT 0123, Minsky et al. established the standard dosage of 5 -FU $\left(1000 \mathrm{mg} / \mathrm{m}^{2} / \mathrm{D}, \mathrm{D} 1-4\right.$ per 4 weeks $)$ in the definitive radio-chemotherapy for esophageal cancer [23]. However, considering the relative smaller body size

Table 4 Prognostic factors by log-rank test and univariate survival analysis ${ }^{a}$ in present study

\begin{tabular}{|c|c|c|c|c|c|}
\hline Factors & Group & Number & $\begin{array}{l}\text { Median } O^{b} \\
\text { (months) }\end{array}$ & $\begin{array}{l}\text { Log-rank test } \\
p \text { value }\end{array}$ & $\begin{array}{l}\text { Univariate analysis } \\
p \text { value }\end{array}$ \\
\hline \multirow[t]{2}{*}{ Age } & $<60$ years & 16 & 14.3 & 0.042 & 0.048 \\
\hline & $\geqq 60$ years & 34 & 11.9 & & \\
\hline \multirow[t]{2}{*}{ Gender } & Male & 42 & 15.0 & 0.365 & 0.334 \\
\hline & Female & 8 & 10.6 & & \\
\hline \multirow[t]{2}{*}{ Staging after surgery } & $|/ I|$ & 17 & 17.2 & 0.355 & 0.359 \\
\hline & III/IV & 33 & 13.8 & & \\
\hline \multirow[t]{2}{*}{$\overline{\text { Chemotherapy regimen }}$} & $\mathrm{TP}$ & 28 & 16.3 & 0.012 & 0.025 \\
\hline & $\mathrm{FP}$ & 22 & 9.8 & & \\
\hline \multirow[t]{2}{*}{ Response to treatment } & $\mathrm{CR} / \mathrm{PR}$ & 40 & 15.0 & 0.071 & 0.072 \\
\hline & SD & 10 & 12.8 & & \\
\hline \multirow[t]{2}{*}{ Irradiation dose } & $\geqq 60$ Gy & 29 & 16.3 & 0.040 & 0.041 \\
\hline & $<60$ Gy & 21 & 11.5 & & \\
\hline
\end{tabular}

$\bar{a}_{\text {: Cox's proportional hazards regression model; }}^{b}$ : Overall survival. 
of the Chinese population, the dosage of 5-FU was consequently decreased, similar in methodology with other Asian studies [12,17].

In addition, our data indicates that an irradiation dose of more than 60 Gy could improve not only the PFS but the OS among those patients with recurrent esophageal cancer after surgery (both $p<0.05$ ). In our opinion, 50.4 Gy was the standard irradiation dose for esophageal cancer reported by Minsky et al. [23] in trial INT 0123 and the higher radiation dose $(64.8 \mathrm{~Gy})$ did not increase the survival or local/regional control. But the authors also pointed out that $63.6 \%(7 / 11)$ the treatment-related deaths in the high-dose arm occurred in patients who received 50.4 Gy or less, and the higher dose of irradiation might not be responsible for the increased mortality. In 2001, reports from Nemoto et al. [8] indicated that no significance between the patients' survival received more than or less than $60 \mathrm{~Gy}$. But the 1-year and 3-year survival rates were $45 \%$ and $20 \%$ in the higher dose arm respectively, which were superior than those of the lower dose arm (15\% and 7\% respectively). In the study by Baxi et al. [15] most patients $(79 \%, 11 / 14)$ received irradiation dose of 58-60 Gy and the median OS (16 months) of all patients was encouraging. And in study by Jingu et al. [17], the irradiation dose was $60 \mathrm{~Gy} / 30$ fractions and the treatment outcomes (median OS of 39 months) were extremlly exciting. To data, one study has indicated that the survival was similar among the patients received an irradiation dose more or less than 60 Gy [14]. After a careful review of the literatures, the suitable irradiation dose for recurrent esophageal cancer remains unclear and requires further investigations.

With regard to the side-effects of concurrent radiochemotherapy for post-operative esophageal cancer, the irradiation dose for the esophago-gastric anastomosis and the gastric tube should be of particularly concerm. In the present study, grade 3 treatment-related gastritis were recorded in 6 patients (27.3\%) and 7 patients (25.0\%) in the R-FP and R-TP group, respectively. One patient received R-TP treatment was observed having the grade 3 vomiting. As far as we know, the prediction probability of the normal tissue complication at 5\% within 5 years after radiotherapy (TD 5/5) of the stomach is 60 Gy [24]. Furthermore, Nemato et al. [8] reported that one patient died of necrosis of the stomach 6 months after comletion of radiation therapy (66 Gy). Therefore, we avoided prescribing a dose of more than $60 \mathrm{~Gy}$ to the recurrence of the anastomotic sites in present study, and only recurrences of the regional lymph nodes received the irradiation dose more than 60 Gy. As a result, no serious treatment-related sideeffects (gastric fistula or necrosis) were observed in the follow-up. Other common toxicities included hematological side-effects (neutropenia and anemia) and digestive tract toxicities in present study. Compared to the previous studies of patients with the locally-advanced esophageal cancer [22,23,25-27], the treatment-related toxicities of the concurrent radio-chemotherapy in present study were similar to or less than the studies mentioned above $[8,12-15,17]$.

One issue should be mentioned here. According to the NCCN guidelines [18], also as summarized by two metaanalysis $[28,29]$, the pre-operative chemoradiation followed by surgery is the most common strategy for patients with resectable esophageal cancer in Western countries, which could significantly improve the 3-year OS and reduce the loco-reginal recurrences. The irradiation dose in such approach is nearly 40-45 Gy. Thus, the patient who received the pre-operative chemoradiation could not be treated with such higher irradiation dose similarly to the present study (around 60 Gy) for loco-regional recurrence. The optimal treatment strategies for this specific group of patients need further clinical studies.

In conclusion, combination of radiotherapy with concurrent FP or TP chemotherapy is a safe and promising salvage treatment for loco-regional recurrence of esophageal cancer after surgery. The use of TP regimen and an irradiation dose of more than 60 Gy may improve the overall survival of these patients. However, the optimal treatment strategy (irradiation dose and chemotherapy regimen) for loco-regional recurrent esophageal cancer warrents further studies.

\section{Competing interests}

The authors declare that they have no competing interests.

\section{Authors' contributions}

JZ, FP and NL contributed equally in collection and analysis of data and drafting the manuscript; YL, YX, LZ, JW, JZ and MH provided the critical revision of the manuscript and the administrative support; $Y G$ provided the conception of this study and the final approval of the version to be published. And all authors read and approved the final manuscript.

\section{Acknowledgement}

We would like to thank Dr. Xin Gao at the Harvard Medical School in United States for the improvement of English language.

Part of the material will be presented in the Digital Poster Discussion session of the 54th Annual Meeting of American Society for Radiation Oncology, Boston, US.

\section{Author details}

${ }^{1}$ Department of Thoracic Oncology and Radiation Oncology, Cancer Center, West China Hospital, Sichuan University, Chengdu 610041, PR China. ${ }^{2}$ State Key Laboratory of Biotherapy, West China Hospital, Sichuan University, Chengdu 610041, PR China. ${ }^{3}$ Department of Oncology, Second Affiliated Hospital of Anhui Medical University, Hefei 230601, PR China.

Received: 14 March 2012 Accepted: 19 June 2012

Published: 19 June 2012

\section{References}

1. Fujita H, Kakegawa T, Yamana H, Shima I, Toh Y, Tomita Y, Fujii T, Yamasaki K, Higaki K, Noake T: Mortality and morbidity rates, post-operative course, 
quality of life, and prognosis after extended radical lymphadenectomy for esophageal cancer. Ann Surg 1995, 222:654-662.

2. Akiyama $H$, Tsurumaru $M$, Udagawa $H$, Kajiyama $Y$ : Radical lymph node dissection for cancer of the thoracic esophagus. Ann Surg 1994, 220:364-373.

3. Ando N, Oazawa S, Kitagawa Y, Shinozawa Y, Kitaijma M: Improvement in the results of treatment of advanced squamous esophageal carcinoma over fifteen consecutive years. Ann Surg 2000, 232:225-232.

4. Bhansali MS, Fujita H, Kakegawa T, Yamana H, Ono T, Hikita S, Toh Y, Fujii T, Tou U, Shirouzu K: Pattern of recurrence after extended radical esophagectomy with three-field lymph node dissection for squamous cell carcinoma in the thoracic esophagus. World J Surg 1997, 21:275-281.

5. Kyriazanos ID, Tachibana M, Shibakita M, Yoshimura H, Kinugasa S, Dhar DK, Nakamoto T, Fujii T, Nagasue N: Pattern of recurrence after extended esophagectomy for squamous cell carcinoma of the esophagus. Hepatogastroenterology 2003, 50:115-120.

6. Raoul JL, Le Prise E, Meunier B, Julienne V, Etienne PL, Gosselin M, Launois $B$ : Combined radiochemotherapy for postoperative recurrence of oesophageal cancer. Gut 1995, 37:174-176.

7. Sato N, Ishida K, Ikeda K, Koeda K, Ohtsuka K, Kimura Y, Aoki K, Ogasawara S, Iwaya T, Saito K: Treatment of patients with recurrent esophageal carcinoma. Gan To Kagaku Ryoho 1998, 25:314-320.

8. Nemoto K, Ariga H, Kakuto Y, Matsushita H, Takeda K, Takahashi C, Takai Y, Yamada S, Hosoi Y: Radiation therapy for loco-regionally recurrent esophageal cancer after surgery. Radiother Oncol 2001, 61:165-168.

9. Urba SG, Chansky K, Van Veldhuizen PJ, Pluenneke RE, Benedetti JK, Macdonald JS, Abbruzzese JL, Southwest Oncology Group Study: Gemcitabine and Cisplatin for patients with metastatic or recurrent esophageal carcinoma: A Southwest Oncolgy Group study. Invest New Drugs 2004, 2:91-97.

10. Fahn HJ, Wang LS, Huang BS, Huang MH, Chien KY: Tumor recurrence in long-term survivors after treatment of carcinoma of the esophagus. Ann Thorac Surg 1994, 57:677-681.

11. Airoldi M, Cortesina G, Giordano C, Pedani F, Bumma C, Gabriele P: Docetaxel and vinorelbine: an effective regimen in recurrent squamous cell esophageal carcinoma. Med Oncol 2003, 20:19-24.

12. Nemoto K, Matsushita H, Ogawa Y, Takeda K, Takahashi C, Britton KR, Takai Y, Miyazaki S, Miyata T, Yamada S: Radiation therapy combined with cisdiammine-glycolatoplatinum (Nedaplatin) and 5 -fluorouracil for untreated and recurrent esophageal cancer. Am J Clin Oncol 2003, 26:46-49.

13. Yamashita H, Nakagawa K, Tago M, Nakamura N, Shiraishi K, Ohtomo K: Salvage radiotherapy for postoperative loco-regional recurrence of esophageal cancer. Dis Esophagus 2005, 18:215-220.

14. Shioyama Y, Nakamura K, Ohga S, Nomoto S, Sasaki T, Yamaguchi T, Toba T, Yoshitake T, Terashima H, Honda H: Radiation therapy for recurrent esophageal cancer after surgery: clinical results and prognostic factors. Jpn J Clin Oncol 2007, 37:918-923.

15. Baxi SH, Burmeister B, Harvey JA, Smithers M, Thomas J: Salvage definitive chemo-radiotherapy for locally recurrent oesophageal carcinoma after primary surgery: retrospective review. J Med Imag Radiat Oncol 2009, 52:583-587.

16. Nakamura T, Ota M, Narumiya K, Sato T, Ohki T, Yamamoto M, Mitsuhashi N: Multimodal treatment for lymph node recurrence of esophageal carcinoma after curative resection. Ann Surg Oncol 2008, 15:2451-2457.

17. Jingu K, Nemoto K, Matsushita H, Takahashi C, Ogawa Y, Sugawara T, Nakata E, Takai Y, Yamada S: Results of radiation therapy combined with nedaplatin (cis-diammine-glycoplatinum) and 5-Fluorouracil for postoperative locoregional recurrent esophageal cancer. BMC Cancer 2006, 6:50.

18. Clinical Practice Guidelines in Oncology: Esophageal cancer. NCCN guidelines version 1. 2009. www.NCCN.org

19. World Medical Association: Declaration of Helsinki. Bull World Health Organ 2001, 79:373-374.

20. AJCC Cancer Staging Manual: American Joint Committee on Cancer. 6th edition. New York: Springer-Verlag; 2002

21. Therasse P, Arbuck SG, Eisenhauer EA, Wanders J, Kaplan RS, Rubinstein L, Verweij J, Van Glabbeke M, van Oosterom AT, Christian MC, Gwyther SG: New guidelines to evaluate the response to treatment in solid tumors. European Organization for Research and Treatment of Cancer, National
Cancer Institute of the United States, National Cancer Institute of Canada. J Natl Cancer Inst 2000, 92:205-216.

22. Ajani JA, Winter K, Komaki R, Kelsen DP, Minsky BD, Liao ZX, Bradley J, Fromm M, Hornback D, Willett CG: Phase II randomized trial of two nonoperative regimens of induction chemotherapy followed by chemoradiation in patients with localized carcinoma of the esophagus: RTOG 0113. J Clin Oncol 2008, 26:4551-4556.

23. Minsky BD, Pajak TF, Ginsberg RJ, Pisansky TM, Martenson J, Komaki R, Okawara G, Rosenthal SA, Kelsen DP: INT 0123 (Radiation Therapy Oncology Group 94-05) phase III trial of combined-modality therapy for esophageal cancer: high-dose versus standard-dose radiation therapy. J Clin Oncol 2002, 20:1167-1174.

24. Emami B, Lyman J, Brown A, Coia L, Goitein M, Munzenrider JE, Shank B, Solin $L$, Wesson M: Tolerance of normal tissue to therapeutic irradiation. Int J Radiat Oncol Biol Phys 1991, 21:109-122.

25. Ohtsu A, Boku N, Muro K, Chin K, Muto M, Yoshida S, Satake M, Ishikura S, Ogino T, Miyata Y, Seki S, Kaneko K, Nakamura A: Definitive chemoradiotherapy for T4 and/or M1 lymph node squamous cell carcinoma of the esophagus. J Clin Oncol 1999, 17:2915-2921.

26. Ishida K, Ando N, Yamamoto S, Ide H, Shinoda M: Phase II study of cisplatin and 5-fluorouracil with concurrent radiotherapy in advanced squamous cell carcinoma of the esophagus: a Japan Esophageal Oncology Group (JEOG)/Japan Clinical Oncology Group Trial (JCOG9516). Jpn J Clin Oncol 2004, 34:615-619.

27. Cooper JS, Guo MD, Herskovic A, Macdonald JS, Martenson JA Jr, Al-Sarraf M, Byhardt R, Russell AH, Beitler JJ, Spencer S, Asbell SO, Graham MV, Leichman LL: Chemoradiotherapy of locally advanced esophageal cancer: long-term follow-up of a prospective randomized trial (RTOG 85-01). Radiation Therapy Oncology Group. J Am Med Assoc 1999, 281:1623-1627.

28. Urschel JD, Vasan H: A meta-analysis of randomized controlled trials that compared neoadjuvant chemoradiation and surgery to surgery alone for resectable esophageal cancer. Am J Surg 2003, 185:538-543.

29. Fiorica F, Di Bona D, Schepis F, Licata A, Shahied L, Venturi A, Falchi AM Craxì A, Cammà C: Preoperative chemoradiotherapy for oesophageal cancer: a systematic review and meta-analysis. Gut 2004, 53:925-930.

doi:10.1186/1748-717X-7-93

Cite this article as: Zhang et al: Salvage concurrent radiochemotherapy for post-operative local recurrence of squamous-cell esophageal cancer. Radiation Oncology 2012 7:93.

\section{Submit your next manuscript to BioMed Central and take full advantage of:}

- Convenient online submission

- Thorough peer review

- No space constraints or color figure charges

- Immediate publication on acceptance

- Inclusion in PubMed, CAS, Scopus and Google Scholar

- Research which is freely available for redistribution 